\title{
Antenatal HIV screening: results from the National Perinatal Survey, France, 2016
}

Thi-Chiên Tran ${ }^{1}$, Josiane Pillonel ${ }^{1}$, Françoise Cazein ${ }^{1}$, Cécile Sommen ${ }^{1}$, Camille Bonnet ${ }^{2}$, Béatrice Blondel ${ }^{2}$, Florence Lot ${ }^{1}$

1. Santé publique France, French national public health agency, Saint-Maurice, France

2. Université de Paris, CRESS, INSERM, INRA, Paris, France

Correspondence: Florence Lot (florence.lot@santepubliquefrance.fr)

Tran Thi-Chiên, Pillonel Josiane, Cazein Françoise, Sommen Cécile, Bonnet Camille, Blondel Béatrice, Lot Florence. Antenatal HIV screening: results from the National Perinatal Survey, France, 2016. Euro Surveill. 2019;24(40):pii=1800573. https://doi.org/10.2807/1560-7917.ES.2019.24.40.1800573

Background: Universal antenatal HIV screening programmes are an effective method of preventing mother-to-child transmission. Aims: To assess the coverage and yield of the French programme on a nationally representative sample of pregnant women, and predictive factors for being unscreened or missing information on the performance/ result of a HIV test. Methods: Data came from the medical records of women included in the cross-sectional 2016 French National Perinatal Survey. We calculated odds ratios (OR) to identify factors for being unscreened for HIV and for missing information by multivariable analyses. Results: Of 13,210 women, 12,782 (96.8\%) were screened for HIV and 134 (1.0\%) were not; information was missing for 294 (2.2\%). HIV infection was newly diagnosed in 19/12,769 (0.15\%) women screened. The OR for being unscreened was significantly higher in women in legally registered partnerships (OR: 1.3; 95\% $\mathrm{Cl}$ : 1.1-1.6), with 1-2 years of post-secondary schooling (OR: 1.6; 95\% Cl: 1.2-2.1), part-time employment (OR: $1.4 ; 95 \% \mathrm{Cl}: 1.1-1.8)$, inadequate antenatal care (OR: $1.9 ; 95 \% \mathrm{Cl}: 1.5-2.4$ ) and receiving care from $>1$ provider (OR: $1.8 ; 95 \% \mathrm{Cl}: 1.1-2.8$ ). The OR of missing information was higher in multiparous women (OR: 1.4; $95 \% \mathrm{Cl}: 1.2-1.5)$ and women cared for by general practitioners (OR: $1.4 ; 95 \% \mathrm{Cl}$ : 1.1-1.9). Conclusions: The French antenatal HIV screening programme is effective in detecting HIV among pregnant women. However, a few women are still not screened and awareness of the factors that predict this could contribute to improved screening levels.

\section{Introduction}

An important route for human immunodeficiency virus (HIV) infection is via mother-to-child transmission (MTCT), which can occur during pregnancy, delivery or through breastfeeding. MTCT is preventable through effective public health measures, including antenatal HIV screening and combined antiretroviral therapy (cART). Since 1993, France has included universal HIV testing in its nationwide antenatal programme [1]. Healthcare professionals are supposed to systematically propose an HIV test to all pregnant women during the first trimester of pregnancy and at least one additional test at the beginning of the third trimester for women at high risk, i.e. injecting drug users, sex workers, as well as those with HIV-infected sex partners, new or multiple sex partners during pregnancy [1-3]. The goal is to test $100 \%$ of women unless they have been tested recently. HIV testing (fourth-generation ELISA) is free in all public or private laboratories if women have a prescription from healthcare professionals [2]. The antenatal programme also recommends eight medical visits and three ultrasound examinations for low-risk, full-term pregnancies [1], which are mostly covered by National Health Insurance Fund in the first months of pregnancy and completely covered from the sixth month of pregnancy, except in the private sector where women have to pay extra costs.

A universal antenatal HIV screening programme enables the best possible perinatal antiretroviral therapy (ART) management for HIV-infected mothers and children and is the most effective method of preventing MTCT [4-8]. Such programmes and subsequent perinatal CART have reduced MTCT rates markedly in Europe: in Sweden, from $24.7 \%$ in the period $1985-1993$ to $0.6 \%$ in the period 1999-2003 [5]; in France, from 20\% before 1994 to $1.5 \%$ in the period $1994-2004$ [4]; and in the United Kingdom (UK), from $2.1 \%$ in the period 2000-2001 to $0.5 \%$ in the period 2010-2011 [8].

Nonetheless, MTCT of HIV infection continues to occur in high-income countries because some women still do not receive or refuse the opportunity for HIV testing, or are diagnosed too late to be able to benefit from CART and can, therefore, transmit HIV [7-12]. A study of children born with perinatal HIV infection from 2006 to 2013 in the UK showed that of the 108 mothers of these children, 67 (60\%) were undiagnosed at delivery [10]. 


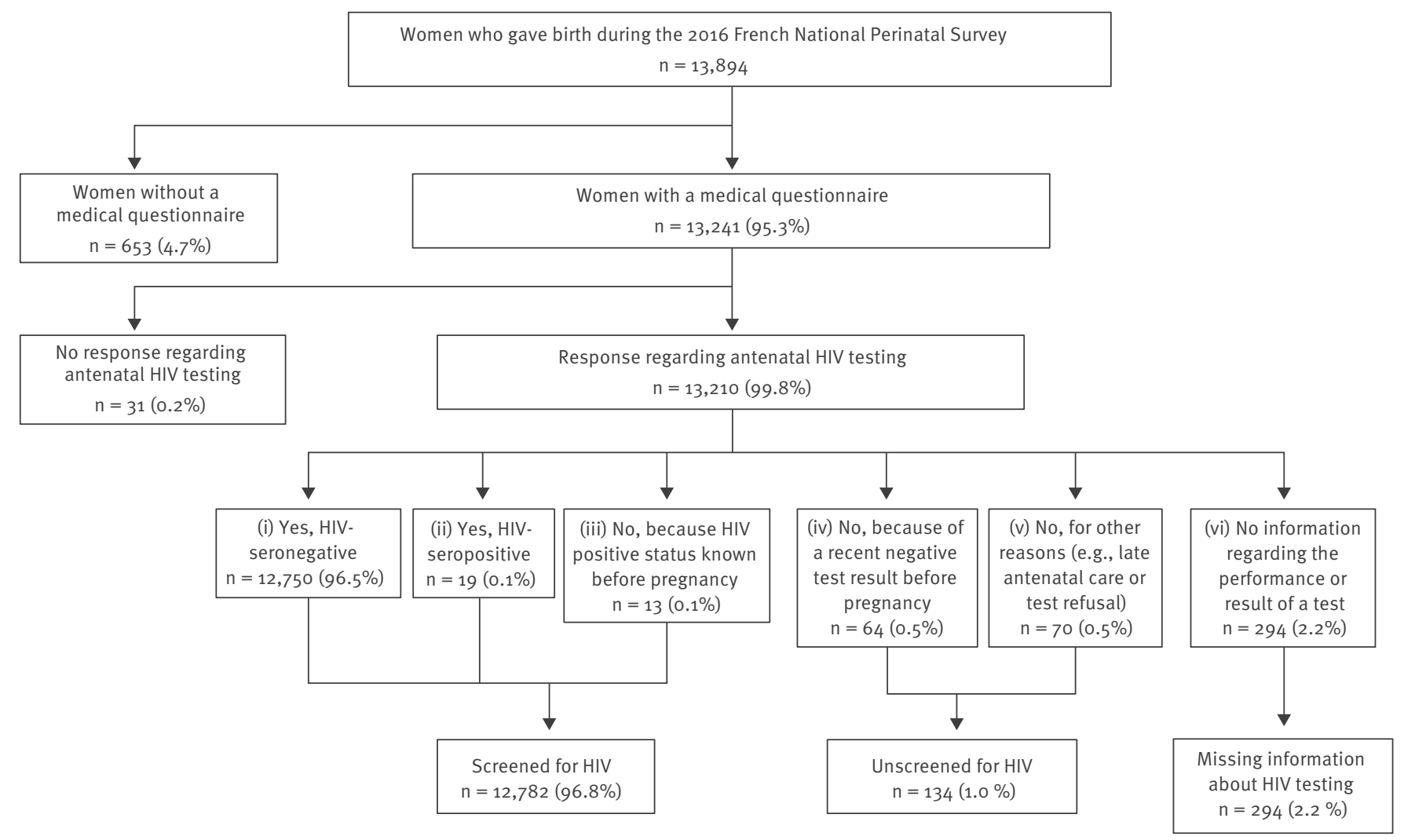

Among them, 28 (41.8\%) had not had antenatal HIV testing, 23 (34.3\%) seroconverted after an earlier HIVseronegative test result during pregnancy, 11 (16.4\%) had a problem with the test because of processing/ reporting errors or late antenatal booking, and information was missing for five women. Similar factors have also been described for perinatally HIV-infected children born in a Parisian hospital from 2006 to 2012 [9].

Mandatory HIV reporting began in France in 2003, with MTCT accounting for $1.0 \%$ of the 73,481 new HIV diagnoses recorded up to 2017. Among 8,463 new diagnoses in women between 2008 and 2017 with a known $\mathrm{CD}_{4}^{+} \mathrm{T}$-cell count, 5,311 (62.8\%) were in women aged 15-39 years. Of these women of childbearing age, $2,731(51.4 \%)$ were diagnosed late $\left(\mathrm{CD}_{4}{ }^{+}<350\right.$ cells/ $\mathrm{mm}^{3}$ at diagnosis).

Interviews after childbirth during the 2010 French National Perinatal Survey (2010 NPS) showed that $68.9 \%$ of 13,891 participating women said that they were tested for HIV during pregnancy; $7.5 \%$ did not know if they had been tested or not; $8.0 \%$ said that they had not been tested because no healthcare provider had proposed it; $4.5 \%$ were not tested because they had had an HIV-negative test result shortly before the pregnancy; $4.6 \%$ were not tested for another reason; $1.0 \%$ refused testing, and; $5.4 \%$ had missing data about antenatal HIV screening [13].
Using data from the 2016 French National Perinatal Survey (2016 NPS), which collected information on HIV screening from medical records, we aimed to assess the present performance of the antenatal HIV screening programme and identify predictive factors associated with being unscreened and missing information about the mother's testing.

\section{Methods}

\section{Study design}

The French National Perinatal surveys are cross-sectional studies designed to monitor perinatal health indicators and to guide health policies $[13,14]$. They include all live births and stillbirths with a gestational age $\geq 22$ weeks or a birth weight $\geq 500$ g occurring in all public and private maternity units over a 1-week period. The 2016 NPS [14] was performed in March 2016.

Three questionnaires were used to collect patient and institutional characteristics: (i) a form completed by investigators during interviews with women in postpartum wards to obtain maternal socio-demographic characteristics and information about antenatal care and delivery (74 questions); (ii) a medical questionnaire completed by investigators using information about antenatal HIV testing, medical, obstetric and perinatal care characteristics extracted from the mothers' medical records (72 questions); (iii) a form where 
TABLE 1

Univariate analysis of antenatal HIV screening according to maternal characteristics, National Perinatal Survey, France, $2016(\mathrm{n}=13,210)$

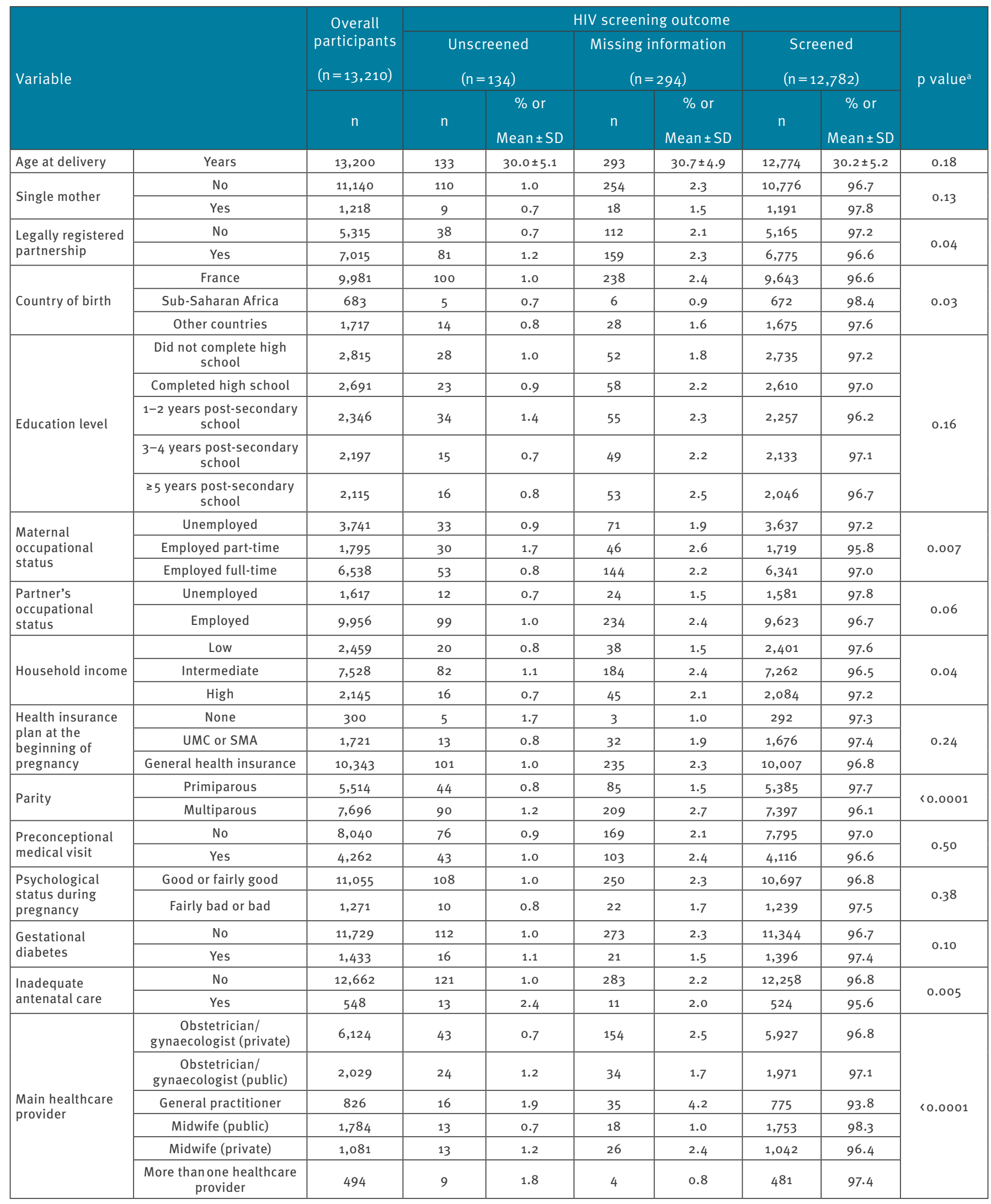

SD: standard deviations; SMA: State Medical Aid; UMC: Universal Medical Coverage.

a $p$ values are referring to differences between the three screening outcomes. 
heads of maternity units described the principal institutional characteristics, e.g. the staff and the organisation of antenatal visits, birth rooms and postnatal care (59 questions). No information was collected on sexual behaviour or intravenous drug use.

All investigators, most of them midwives, were trained how to conduct the survey.

\section{Categories of maternal characteristics and type} of antenatal care

Legally registered partnerships include those in legal marriages or with civil unions, which are known in France as civil solidarity pacts. Single mothers were considered women who did not live with their partner during pregnancy. Women whose monthly household income wasless than EUR 1,500 were defined as lowincome, EUR 1,500-4,000 as intermediate-income, and more than EUR 4,000 as high-income.

In France, women can choose the health professional who will monitor their pregnancy. The main healthcare provider in the first 6 months of pregnancy was classified into six categories: (i) obstetrician and/ or gynaecologist in private practice; (ii) obstetrician/ gynaecologist in public practice; (iii) general practitioner (GP) in the private sector; (iv) midwife in the public sector; ( $v$ ) midwife in the private sector; and (iv) more than one healthcare provider if women were cared for by different doctors or midwives in Maternal and Child Health centres or bymore than one medical professional in different practices.

Women with inadequate antenatal care were defined as those who had fewer than the minimum number of antenatal visits or ultrasound examinations recommended in France for gestational age at delivery.

For the analysis, France was divided into 13 administrative regions: 12 regions of mainland France (Corsica was included in the Provence-Alpes-Côte d'Azur region) and the overseas region (including Guadeloupe, Guyana, Martinique, Mayotte and La Réunion).

\section{Outcomes measured}

The medical questionnaire completed by investigators allowed for six different responses about HIV testing during pregnancy: (i) Yes, HIV-seronegative; (ii) Yes, HIV-seropositive; (iii) No, because HIV-positive status was known before pregnancy; (iv) No, because of a recent negative test result before pregnancy; (v) No, for other reasons, e.g. late antenatal care or test refusal, and; (vi) No information regarding the performance or the result of a test.

The three possible antenatal HIV screening outcomes were: (i) screened if women were tested for HIV during pregnancy or knew their HIV-infection before pregnancy (response i to iii above); (ii) unscreened if women were not tested during pregnancy (response iv or $v$ above); and (iii) missing information (response vi above).
In our analysis, we excluded women for whom investigators did not respond to the question about HIV testing in in the medical questionnaire.

\section{Statistical analysis}

We selected 17 covariables considered to be possible confounders of the outcome from the literature $[7,8,10,11,14-16]$.

In the univariate analyses, the differences between HIV screening groups were assessed by Kendall tests for continuous variables and Pearson's chi-squared tests for qualitative variables. Maternal age was tested both as a continuous variable and a categorical variable according to the following age groups: $<20$ years, 20-24 years, 25-29 years, 30-34 years, 35-39 years, 40-44 years and $\geq 45$ years.

In the multivariable analyses, we started by verifying the missing-data assumptions for the covariables. Then, we used a multiple imputation (MI) procedure by fully conditional specification methods [17] to handle missing covariable values and minimise the bias they could cause. Overall, 116 variables with missing data $<20 \%$ were selected in the $\mathrm{MI}$ model to generate seven imputed datasets [17].

Covariables with a $p$ value $\mathbf{0 . 2}$ in the univariate analyses were adjusted in stepwise multinomial logit models [18] that were applied to the imputed datasets. Only variables with a $p$ value $<0.05$ were retained in the final model to determine predictive factors for the odds of unscreened or missing information outcomes.

Sensitivity analyses compared the results obtained from the same final model across the imputed datasets and the complete database before imputation (raw database).

Based on the plot of the standardised residuals and robust regressions, diagnostics to check the multiple analyses were performed to ensure the quality and the reliability of the results of each multivariate model.

The statistical associations of factors associated with HIV screening are expressed as odds ratios (OR) with their corresponding 95\% confidence intervals (Cl).

The statistical analyses were performed with SAS software version 9.4 (SAS Inc., Cary, North Carolina, United States (US)).

\section{Ethical statement}

The survey was approved by the National Council on Statistical Information, the French Data Protection Authority and the ethics committee of the National Institute for Health and Medical Research. The approval numbers respectively were 2016 703 SA, 915197 and IRBooo03888 no. 14-191. 
Univariate analysis of antenatal HIV screening according to maternity unit characteristics, National Perinatal Survey, France, $2016(\mathrm{n}=13,210)$

\begin{tabular}{|c|c|c|c|c|c|c|c|c|c|}
\hline \multirow{3}{*}{\multicolumn{2}{|c|}{ Variable }} & \multirow{3}{*}{$\begin{array}{c}\text { Overall } \\
\text { participants } \\
(\mathrm{n}=13,210) \\
n\end{array}$} & \multicolumn{6}{|c|}{ HIV screening outcome } & \multirow{3}{*}{$p$ value $^{a}$} \\
\hline & & & \multicolumn{2}{|c|}{$\begin{array}{l}\text { Unscreened } \\
\qquad(n=134)\end{array}$} & \multicolumn{2}{|c|}{$\begin{array}{l}\text { Missing } \\
\text { information } \\
(n=294)\end{array}$} & \multicolumn{2}{|c|}{$\begin{array}{l}\text { Screened } \\
(n=12,782)\end{array}$} & \\
\hline & & & $\mathrm{n}$ & $\%$ & $n$ & $\%$ & $\mathrm{n}$ & $\%$ & \\
\hline \multirow{13}{*}{$\begin{array}{l}\text { Location of maternity } \\
\text { unit, region }\end{array}$} & Paris region $^{b}$ & 3,013 & 8 & 0.3 & 13 & 0.4 & 2,992 & 99.3 & \multirow{13}{*}{$<0.0001$} \\
\hline & Grand-Est & 1,040 & 20 & 1.9 & 35 & 3.4 & 985 & $94 \cdot 7$ & \\
\hline & Nouvelle-Aquitaine & 924 & 8 & 0.9 & 32 & $3 \cdot 5$ & 884 & $95 \cdot 7$ & \\
\hline & Bourgogne-Franche-Comté & 458 & 3 & 0.7 & 14 & 3.1 & 441 & 96.3 & \\
\hline & Bretagne & 586 & 15 & 2.6 & 12 & 2.0 & 559 & 95.4 & \\
\hline & Centre-Val-de-Loire & 465 & 12 & 2.6 & 8 & 1.7 & 445 & 95.7 & \\
\hline & Occitanie & 956 & 6 & 0.6 & 36 & 3.8 & 914 & 95.6 & \\
\hline & Hauts-de-France & 1,209 & 8 & 0.7 & 21 & 1.7 & 1,180 & 97.6 & \\
\hline & Normandie & 649 & 1 & 0.2 & 8 & 1.2 & 640 & 98.6 & \\
\hline & Provence-Alpes-Côte d'Azur ${ }^{\mathrm{c}}$ & 841 & 12 & 1.4 & 13 & 1.5 & 816 & 97.0 & \\
\hline & Pays de la Loire & 770 & 26 & $3 \cdot 4$ & 70 & 9.1 & 674 & $87 \cdot 5$ & \\
\hline & Auvergne-Rhône-Alpes & 1,574 & 12 & 0.8 & 31 & 2.0 & 1,531 & 97.3 & \\
\hline & Overseas $^{d}$ & 696 & 3 & 0.4 & 1 & 0.1 & 692 & 99.4 & \\
\hline \multirow{6}{*}{$\begin{array}{l}\text { Size of maternity unit, } \\
\text { annual deliveries }\end{array}$} & $<500$ & 345 & 4 & 1.2 & 10 & 2.9 & 331 & $95 \cdot 9$ & \multirow{6}{*}{0.76} \\
\hline & $500-999$ & 1,879 & 21 & 1.1 & 42 & 2.2 & 1,816 & 96.6 & \\
\hline & $1,0001,499$ & 2,076 & 16 & 0.8 & 47 & 2.3 & 2,013 & 97.0 & \\
\hline & $1,500-1,999$ & 1,954 & 19 & 1.0 & 51 & 2.6 & 1,884 & 96.4 & \\
\hline & $2,000-3,499$ & 4,658 & 45 & 1.0 & 102 & 2.2 & 4,511 & 96.8 & \\
\hline & $\geq 3,500$ & 2,247 & 29 & 1.3 & 42 & 1.9 & 2,176 & 96.8 & \\
\hline
\end{tabular}

a $p$ values are referring to differences between the three screening outcomes.

b The île-de-France region is known as the Paris region.

' The region of Corsica is included in the Provence-Alpes-Côte d'Azur region.

¿ Guadeloupe, Guyana, Martinique, Mayotte and La Réunion were grouped together as the Overseas region.

\section{Results}

\section{Study participation}

Overall, 4 of 517 (0.8\%) maternity units in France refused participation in the 2016 NPS, corresponding to about 120 missing births. In the 513 participating units, 14,142 infants were born to 13,894 women during the survey period. The medical questionnaire was available for 13,241 women (95.3\%) aged 17 to 49 years (Figure).

Among the 653 women without a medical questionnaire, $206(31.5 \%)$ refused to participate in the survey, 227 (34.8\%) were not interviewed because of concerns raised by the data protection committee (minors, women with stillbirths, or planned surrenders for adoption), and 220 (33.7\%) could not participate because of language barriers, health problems or early discharge from the maternity unit.
Among the 13,241 women with a medical questionnaire, $31(0.2 \%)$ were excluded because no response was given to the question regarding HIV testing. Maternal socio-demographic characteristics and maternity unit characteristics did not differ between the women excluded and those included, overall or by screening outcome category, i.e. screened, unscreened and missing information.

Missing data accounted for $0 \%-8 \%$ of the values for $16 / 17$ covariables, reaching $12 \%$ in the remaining covariate (partner's occupational status).

\section{HIV screening}

Among the 13,210 women included in our analysis, antenatal HIV screening was performed for 12,782 (96.8\%), not performed for 134 (1.0\%) and information was missing for 294 (2.2\%) (Figure).

Among the 134 unscreened women, 64 (47.8\%) were not tested because of a recent negative HIV test result 


\section{TABLE 3}

Adjusted odds ratios of being unscreened for HIV and missing information about an HIV test, National Perinatal Survey, France, $2016(\mathrm{n}=13,210)$

\begin{tabular}{|c|c|c|c|}
\hline \multirow{3}{*}{ Variable } & & \multicolumn{2}{|c|}{ HIV screening outcome ${ }^{a}$} \\
\hline & & \multirow{2}{*}{$\begin{array}{c}\text { Unscreened vs } \\
\text { screened } \\
\text { aOR }(95 \% \mathrm{Cl})\end{array}$} & \multirow{2}{*}{$\begin{array}{c}\text { Missing information vs } \\
\text { screened } \\
\text { aOR }(95 \% \mathrm{Cl})\end{array}$} \\
\hline & & & \\
\hline \multirow{2}{*}{ Legally registered partnership } & No & Reference & Reference \\
\hline & Yes & $1.29(1.08-1.55)$ & $0.95(0.84-1.07)$ \\
\hline \multirow{5}{*}{ Education level } & Did not complete high school & $0.99(0.71-1.38)$ & $0.79(0.62-1.00)$ \\
\hline & Completed high school & $0.95(0.67-1.35)$ & $0.97(0.79-1.19)$ \\
\hline & 1-2-years post-secondary school & $1.56(1.19-2.06)$ & $1.04(0.84-1.29)$ \\
\hline & 3-4-years post-secondary school & $0.74(0.50-1.09)$ & $1.04(0.83-1.29)$ \\
\hline & $\geq 5$-years post-secondary school & Reference & Reference \\
\hline \multirow{3}{*}{ Maternal occupational status } & Unemployed & Reference & Reference \\
\hline & Employed part-time & $1.44(1.13-1.84)$ & $1.06(0.87-1.30)$ \\
\hline & Employed full-time & $0.82(0.64-1.04)$ & $0.96(0.82-1.13)$ \\
\hline \multirow{2}{*}{ Parity } & Primiparous & Reference & Reference \\
\hline & Multiparous & $1.14(0.97-1.34)$ & $1.37(1.23-1.54)$ \\
\hline \multirow{6}{*}{ Main healthcare provider } & Obstetrician/gynaecologist (private) & $0.65(0.49-0.87)$ & $1.28(1.06-1.53)$ \\
\hline & Obstetrician/gynaecologist (public) & $1.09(0.78-1.53)$ & $0.81(0.61-1.07)$ \\
\hline & General practitioner & $1.21(0.80-1.82)$ & $1.43(1.06-1.92)$ \\
\hline & Midwife (public) & Reference & Reference \\
\hline & Midwife (private) & $0.98(0.64-1.51)$ & $1.05(0.77-1.43)$ \\
\hline & More than one healthcare provider & $1.75(1.10-2.78)$ & $1.13(0.75-1.69)$ \\
\hline \multirow{2}{*}{ Inadequate antenatal care } & No & Reference & Reference \\
\hline & Yes & $1.89(1.47-2.44)$ & $1.20(0.91-1.57)$ \\
\hline \multirow{13}{*}{ Location of maternity units } & Paris region ${ }^{b}$ & Reference & Reference \\
\hline & Grand-Est & $2.43(1.60-3.69)$ & $2.00\left(1.45^{-2.76)}\right.$ \\
\hline & Nouvelle-Aquitaine & $1.11(0.61-2.02)$ & $2.05(1.47-2.85)$ \\
\hline & Bourgogne-Franche-Comté & $0.73(0.29-1.86)$ & $1.88(1.19-2.98)$ \\
\hline & Bretagne & $3.22(2.02-5.13)$ & $1.14(0.70-1.86)$ \\
\hline & Centre-Val-de-Loire & $3.13(1.88-5.19)$ & $0.98\left(0.55^{-1.76)}\right.$ \\
\hline & Occitanie & $0.78(0.40-1.53)$ & $2.12(1.54-2.92)$ \\
\hline & Hauts-de-France & $0.75(0.41-1.36)$ & $1.02(0.69-1.50)$ \\
\hline & Normandie & $0.17(0.03-0.80)$ & $0.72(0.40-1.28)$ \\
\hline & Provence-Alpes-Côte d'Azur ${ }^{c}$ & $1.63(0.98-2.70)$ & $0.84(0.53-1.35)$ \\
\hline & Pays de la Loire & $4.06(2.73-6.04)$ & $5.24(3.98-6.88)$ \\
\hline & Auvergne-Rhône-Alpes & $0.89(0.54-1.46)$ & $1.11(0.80-1.55)$ \\
\hline & Overseas $^{d}$ & $0.30(0.11-0.80)$ & $0.07(0.01-0.32)$ \\
\hline
\end{tabular}

$\mathrm{Cl}$ : confidence interval; aOR: adjusted odds ratio.

a Screened $(n=12,782)$; unscreened $(n=134)$; missing information $(n=294)$.

b The Île-de-France region is known as the Paris region.

' The region of Corsica is included in the Provence-Alpes-Côte d'Azur region.

d Guadeloupe, Guyana, Martinique, Mayotte and La Réunion were grouped together as the Overseas region.

The association of each indicator with HIV screening was estimated by its aOR and $95 \% \mathrm{Cl}$, obtained from a multiple multinomial logit model applied to seven imputed datasets. Each dataset contained 13,210 pregnant women. 
before pregnancy and 70 (52.2\%) for other reasons (e.g. late antenatal care, test refusal).

Of the 12,782 screened, 13 were not tested because they were already known to be HIV-positive before pregnancy. HIV infection was newly diagnosed in 19 (0.15\%) of 12,769 women tested during pregnancy.

\section{Maternal characteristics according to HIV screening}

In univariate analyses, among the demographic and social characteristics associated with HIV screening with a $p$ value 0.05 , the proportion of women screened was higher among those not in a legally registered partnership (97.2\%), born outside France $(\geq 97.6 \%)$, unemployed $(97.2 \%)$ or employed full-time (97.0\%), and those who had a low-income (97.6\%) or a high-income $(97.2 \%)$ (Table 1$)$. The percentage of unscreened women washigher among those in a legally registered partnership (1.2\%) or with part-time employment $(1.7 \%)$ or with an intermediate-income (1.1\%). We also found higher missing information outcomes for women in a legally registered partnership, born in France, with part-time employment or with an intermediate-income.

Among the obstetric characteristics, parity affected outcome most strongly. Unscreened and missing information outcomes were more frequent among multiparous than primiparous women (1.2\% vs $0.8 \%$ and $2.7 \%$ vs $1.5 \%$, respectively, $p$ value $<0.0001$ ). In all, $58.3 \%$ of the participants were multiparous and accounted for $67.2 \%(n=90)$ of the 134 unscreened women and 13 of 19 new HIV diagnoses during pregnancy.

The proportion of women with unscreened and missing information outcomes also differed significantly according to antenatal care ( $p$ value $\leq 0.005$ ). Women with inadequate antenatal care had a higher rate of unscreened outcomes (2.4\% vs $1.0 \%$ ) and a lower rate of missing information (2.0\% vs $2.2 \%$ ) than those without inadequate antenatal care. Both outcomes were also highest among women cared for by a GP compared with those cared for by another healthcare provider in the first 6 months of pregnancy $(1.9 \%$ vs $0.7-1.8 \%$ for unscreened and $4.2 \%$ vs $0.8-2.5 \%$ for missing information). The second-highest rate of unscreened outcomes and the lowest rate of missing information outcomes were found in women receiving care frommore than one healthcare provider ( $1.8 \%$ and $0.8 \%$, respectively). The lowest rate of unscreened outcomes was found in women receiving care from a public midwife (0.7\%) or a private obstetrician/gynaecologist (0.7\%).

We found no association ( $p$ value $0.05-0.2$ ) between the outcome and maternal age as a continuous variable, single mothers, education level, partner's occupation, or gestational diabetes.

The outcome did not differ ( $p>0.2)$ according to maternal age as a categorical variable (data not shown), type of health insurance, preconceptional medical visit, or any of psychological status during pregnancy.

\section{Maternity unit characteristics according to HIV screening}

The proportions of unscreened and missing information outcomes differed substantially according to the region where the maternity unit was located but not according to its size. Specifically, unscreened and missing information outcomes were lowest, respectively, among women who gave birth in maternity units of the Paris (0.3\% and $0.4 \%$ ), Normandie (0.2\% and $1.2 \%$ ) and Overseas (0.4\% and $0.1 \%$ ) regions and highest in the Pays de la Loire (3.4\% and 9.1\%) and Grand-Est (1.9\% and $3.4 \%$ ) regions (Table 2 ).

\section{Predictive factors for odds of unscreened or missing information outcomes}

In the multivariate analysis, several factors were each independently associated with the odds of being unscreened including; legally registered partnership, education level, occupational status, inadequate antenatal care, healthcare provider and maternity region (Table 3). Parity, healthcare provider and maternity region were each independently associated with the odds that information about HIV screening was missing (Table 3).

The odds of an unscreened outcome was significantly higher in women in a legally registered partnership (OR: $1.3 ; 95 \% \mathrm{Cl}: 1.1-1.6), 1-2$ years of post-secondary schooling (OR:1.6; 95\% Cl: 1.2-2.1) and part-time employment (OR: $1.4 ; 95 \% \mathrm{Cl}: 1.1-1.8)$. The odds of a missing information outcome was higher among multiparous women (OR: $1.4 ; 95 \% \mathrm{Cl}: 1.2-1.5$ ).

Women with inadequate antenatal care were more likely to be unscreened for HIV (OR: 1.9; 95\% Cl: 1.5-2.4) than those whose antenatal care was adequate.

The odds of an unscreened outcome was significantly lower for women cared for by an obstetrician/gynaecologist in private practice (OR: $0.7 ; 95 \% \mathrm{Cl}: 0.5-0.9$ ) but higher for women receiving care frommore than one healthcare provider (OR: $1.8 ; 95 \% \mathrm{Cl}: 1.1-2.8)$ than any of the others. Information about HIV screening was missing more often in women cared for by an obstetrician/gynaecologist in private practice (OR:1.3; $95 \% \mathrm{Cl}$ : 1.1-1.5) or a GP (OR: $1.4 ; 95 \% \mathrm{Cl}: 1.1-1.9)$ than those cared for by the other healthcare providers.

The odds of an unscreened outcome was significantly higher for women in the Grand-Est, Bretagne, Centre, and Pays de la Loire regions, and lower for those in the Normandie and Overseas regions. Similarly, the odds of a missing information outcome was higher for women in the Grand-Est and Pays de la Loire regions and lower for those in the Overseas region. It was also higher in the Nouvelle-Aquitaine, Bourgogne FrancheComté and Occitanie regions. 
Sensitivity analyses for multivariate regression performed on the complete pre-imputation database produced similar results (Supplementary Table S1).

\section{Discussion}

This study shows a high rate of antenatal HIV screening among pregnant women living in France (96.8\%). Screening resulted in the discovery of 19 new cases of HIV infection among women tested during pregnancy (0.15\%), even though some pregnant women were not offered or refused the opportunity for antenatal HIV testing $(1.0 \%)$ or their medical records had no information on the performance or the result of a HIV test (2.2\%).

Among high-income countries, only the Netherlands [7] has previously evaluated its universal antenatal HIV screening programme. The proportion of HIV screening among women who gave birth in the Netherlands in 2006 to 2008 was higher than in France in 2016 (99.8\% vs $96.8 \%$ ). This difference is likely because of the use of different data sources; the Dutch study collected information about antenatal HIV testing from a national electronic database while ours was based on the use of medical records with a relatively high rate of missing information about HIV testing (2.2\%).

The practical effectiveness of the French antenatal HIV testing programme is demonstrated by the absence of significant associations between HIV screening and maternal country of birth, single motherhood, household income or health insurance plan. Nonetheless, some women still receive inadequate antenatal care, which was associated with higher odds of not being screened. This finding is similar to that of Breese et al. who concluded that a lack of HIV screening was associated with a lack of antenatal care in women who gave birth between 1998 and 2001 in a Colorado, US hospital [15]. This association was also found in the Lazio region, Italy by Valle et al. [11]. In France, women with inadequate antenatal care were found to be principally women who made their first antenatal visit too late, after the first trimester of pregnancy [19]. Inadequate care is more frequent in women who are younger, multipara, migrant, single, living in deprived neighbourhoods, do not have health insurance or have a low educational level $[19,20]$.

Our results also showed that women in a legally registered partnership or with 1-2 years of post-secondary education or with part-time employment had significantly higher odds of not being screened. Several hypotheses might explain these results.

Women in legally registered partnerships might be considered at low risk of HIV infection on the assumption that they only have one sexual partner. Healthcare providers might therefore not routinely offer them HIV screening.
The higher odds observed for no testing in women with an intermediate education level could be explained by differences in health literacy and inequities in care. Healthcare providers may think, for example, that the risk of HIV exposure for women decreases with increasing education level and thus women with a lower educational may be prescribed HIV testing more often as a result; these women may also be more closely followed up more to ensure that they are tested. Indeed, educational disparities can impair low-educated women's knowledge or ability to engage in preventive health behaviours leaving them vulnerable to HIV and other diseases [21]. Conversely, highly educated women, i.e. those with 3 or more years post-secondary schooling, may have a greater awareness and understanding of the testing recommendations and therefore be more likely to adhere to them. In comparison with low and high-educated women, women with an intermediate level of education level may have less attention from health professionals about HIV testing and less ability to understand the importance of it.

In terms of an explanation for a significantly higher odds of unscreened outcomes for women working part-time, we suggest that socioeconomic factors might have an indirect influence even though being unscreened was not significantly associated with the mother's household income in our multivariate analyses. In a report about part-time employed women, the French Economic, Social and Environmental Council [22] revealed that part-time employment was more common in women with a low education level, a lowskill job or those living in rural areas. Women with parttime employment may thus have more restrictions on their outcome and the organisation of their pregnancy follow-up, which could reduce their opportunities to access HIV testing. Furthermore, part-time employment is a factor that increased socioeconomic inequalities as it is not a personal choice for one-third of women [22].

The higher odds of missing information about HIV screening in the medical records of multiparous women might be because of providers assuming that a test was performed in a previous pregnancy and that nothing has changed.

The odds of not being screened for-HIV was notably higher for women with more than one care provider in the first 6 months of pregnancy. This may not only suggest a lack of HIV screening but also of follow-up antenatal care among these women. A significantly higher odds of missing information about HIV testing was also found among women receiving antenatal care from GPs or obstetricians/gynaecologists in private practice during the first 6 months of pregnancy. These women only booked appointments in maternity units for delivery after the sixth month of pregnancy and the results of their earlier antenatal examinations should have been transferred. However, HIV test information might have been lost because of the transfer and not checked for at the maternity unit. Our findings should alert obstetrics professionals to think about HIV testing 
at each antenatal visit, especially for women with late booking in maternity units for delivery. Moreover, all maternity units should make sure they collect and record the result of any HIV tests in the medical record of all women.

HIV infection rates differ between areas. In France, the rate of people newly diagnosed with HIV in 2015 was substantially higher in the Paris region (208 per million inhabitants) and the Overseas region (214 per million) than in the other regions (between 28 and 85 per million) [23]. In this epidemiological context and consistent with French HIV screening recommendations, the HIV testing rates are higher among the general population of people from high-prevalence regions [16]. Thus, the highest proportion of screened women was in those who gave birth in the Overseas and Paris regions or those born in sub-Saharan Africa (98.4\%).

Our results appear robust after sensitivity analyses. Additionally, antenatal HIV screening information was collected from medical records in 2016 and is thus more reliable than that collected from interviews in previous years [13]. This study's use of data from the nationally representative sample of pregnant women in France in 2016 is its principal strength.

Nonetheless, our study still presents several limitations. First, we did not know the exact proportion of HIV test refusals because the reasons for being unscreened were not documented. Moreover, for unscreened women with a recent negative HIV test result before pregnancy, we neither know when this test was performed nor if they refused a new one or if a new one was not offered. Furthermore, as the date of HIV screening during pregnancy was not available in 2016 NPS, we did not know if HIV testing was performed during the first trimester or later or repeated.

In conclusion, our study shows inadequate antenatal care as an important indicator for HIV screening and multipara as a risk factor for missing information on HIV testing. Our results also suggest that women perceived as low risk by providers, i.e. legally registered partnerships, were less likely to be screened for HIV while screening is well performed among women who were born outside France, who were unemployed or who had a low income. Although some women do not receive or take advantage of this opportunity, our findings demonstrate that the antenatal HIV screening programme is effective in detecting HIV among pregnant women in France, i.e. has high coverage and yield, and that antenatal HIV screening should continue to be carried out for all pregnant women: healthcare providers should systematically propose HIV testing for all women during the first trimester of pregnancy, and at least propose a repeat test at the beginning of the third trimester for women at high risk. Finally, to improve our understanding of why sometimes HIV screening is not performed and why there is no information on the performance or result of a HIV test in women's medical records, further studies of the attitudes and practices of healthcare providers about antenatal HIV screening in relation to maternal characteristics would be beneficial.

\section{Acknowledgements}

We thank the Maternal and Child Health Services in each district, the department heads and the investigators who participated in the survey, as well as all women who agreed to be interviewed.

Funding: The 2016 National Perinatal Survey was supported by the French Ministry of Health (Direction de la Recherche, des Etudes, de l'Evaluation et des Statistiques (DREES), Direction Générale de la Santé (DGS) and Direction Générale de l'Organisation des Soins (DGOS)) and by Santé publique France.

\section{Conflict of interest}

None declared.

\section{Authors' contributions}

Thi-Chien TRAN: conception and design, analysis and interpretation of data, statistical analysis, drafting of the manuscript. Josiane PILLONEL: critical revision of the manuscript for important intellectual content. Françoise CAZEIN: critical revision of the manuscript for important intellectual content. Cécile SOMMEN: critical revision of the manuscript for analysis of data. Camille BONNET: acquisition of data. Béatrice BLONDEL: acquisition of data, critical revision, administrative. Florence LOT: Corresponding author, critical revision, supervision, administrative.

\section{References}

1. Haute Autorité de Santé (HAS). Suivi et orientation des femmes enceintes en fonction des situations à risque identifiées. [Follow-up and orientation of pregnant women according to identified risk exposures]. Paris: HAS. [Accessed 8 Oct 2018]. French. Available from: https://www.has-sante.fr/portail/

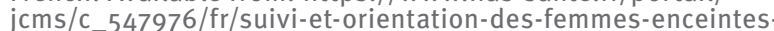
en-fonction-des-situations-a-risque-identifiees

2. Haute Autorité de Santé (HAS), Réévaluation de la stratégie de dépistage de l'infection à VIH en France. [Reassessment of the HIV screening strategy in France]. Paris: HAS. [Accessed 22 Jan 2019]. French. Available from: https://www.hassante.fr/portail/upload/docs/application/pdf/2017-03/dir2/ reevaluation de la strategie depistage vih - synthese conclusions_reco.pd $\overline{d f}$

3. Conseil national du sida et des hépatites virales (CNS). Mandelbrot L. Désir d'enfant et grossesse. Prise en charge médicale des personnes vivant avec le VIH - Recommandations du groupe d'experts sous la direction du Pr Philippe Morlat. [Child's desire and pregnancy. Medical management of people living with HIV. Recommendations of the experts group directed by Philippe Morlat]. Paris: CNS; [Accessed 22 Jan 2019]. French. Available from: https://cns.sante.fr/actualites/ prise-en-charge-du-vih-recommandations-du-groupe-dexperts/

4. Jasseron C. Prise en charge des femmes enceintes infectées par le VIH en France à l'ère des multithérapies : des recommandations aux pratiques. [Access to prevention of mother to child HIV transmission in the multitherapy area: implementation of the guidelines]. Paris. [Accessed 24 Sep 2019]. French. Available from: http://www.theses. $\mathrm{fr} / 2012$ PA11T078

5. Navér L, Lindgren S, Belfrage E, Gyllensten K, Lidman K, Gisslén M, et al. Children born to HIV-1-infected women in Sweden in 1982-2003: trends in epidemiology and vertical transmission. J Acquir Immune Defic Syndr. 2006;42(4):484-9. https://doi.org/10.1097/01.qai.0000224571.30119.3d PMID: 16810115 
6. Patterson KB, Leone PA, Fiscus SA, Kuruc J, McCoy SI, Wolf $L$, et al. Frequent detection of acute HIV infection in pregnant women. AIDS. 2007;21(17):2303-8. https://doi.org/10.1097/ QAD.ob013e3282f155da PMID: 18090278

7. Op de Coul EL, Hahné S, van Weert YW, Oomen P, Smit C, van der Ploeg KP, et al. Antenatal screening for HIV, hepatitis B and syphilis in the Netherlands is effective. BMC Infect Dis. 2011;11(1):185. https://doi.org/10.1186/1471-2334-11-185 PMID: 21718466

8. Townsend CL, Byrne L, Cortina-Borja M, Thorne C, de Ruiter A, Lyall H, et al. Earlier initiation of ART and further decline in mother-to-child HIV transmission rates, 2000 2011. AIDS. 2014;28(7):1049-57. https://doi.org/10.1097/ QAD.0000000000000212 PMID: 24566097

9. Frange $P$, Chaix ML, Veber F, Blanche S. Missed opportunities for HIV testing in pregnant women and children living in France. Pediatr Infect Dis J. 2014;33(2):e60-2. https://doi. org/10.1097/INF.ob013e3182a09120 PMID: 24108234

10. Peters H, Thorne C, Tookey PA, Byrne L. National audit of perinatal HIV infections in the UK, 2006-2013: what lessons can be learnt? HIV Med. 2018;19(4):280-9. https://doi. org/10.1111/hiv.12577 PMID: 29336508

11. Valle S, Pezzotti P, Floridia M, Pellegrini MG, Bernardi S, Puro $V$, et al. Percentage and determinants of missed HIV testing in pregnancy: a survey of women delivering in the Lazio region, Italy. AIDS Care. 2014;26(7):899-906. https://doi.org/10.1080/ 09540121.2013.861572 PMID: 24279737

12. Pauly F, Freese AL, Golic M, Henrich W, Weizsaecker K. Testing for HIV during pregnancy: 5 years after changing German pregnancy guidelines. Arch Gynecol Obstet. 2013;288(1):29-32. https://doi.org/10.1007/s00404-013-2744-9 PMID: 23385348

13. Blondel B, Lelong N, Kermarrec M, Goffinet FCoordination nationale des Enquêtes Nationales Périnatales. La santé périnatale en France métropolitaine de 1995 à 2010. Résultats des enquêtes nationales périnatales [Trends in perinatal health in France between 1995 and 2010: Results from the National Perinatal Surveys]. J Gynecol Obstet Biol Reprod (Paris). 2012;41(2):151-66. https://doi.org/10.1016/j.jgyn.2011.11.008 PMID: 22197351

14. Blondel B, Coulm B, Bonnet C, Goffinet F, Le Ray CNational Coordination Group of the National Perinatal Surveys. Trends in perinatal health in metropolitan France from 1995 to 2016: Results from the French National Perinatal Surveys. J Gynecol Obstet Hum Reprod. 2017;46(10):701-13. https://doi. org/10.1016/j.jogoh.2017.09.002 PMID: 29031048

15. Breese P, Burman W, Shlay J, Guinn D. The effectiveness of a verbal opt-out system for human immunodeficiency virus screening during pregnancy. Obstet Gynecol. 2004;104(1):1347. https://doi.org/10.1097/01.AOG.0000129957.35105.d4 PMID: 15229012

16. Cazein F, Le Strat F, Sarr A, Ramus C, Bouche N, Comboroure JC, et al. Dépistage de l'infection par le VIH en France en 2016. Bull Epidemiol Hebd (Paris). 2017; (29-30):601-8.

17. Lee KJ, Carlin JB. Multiple imputation for missing data: fully conditional specification versus multivariate normal imputation. Am J Epidemiol. 2010;171(5):624-32. https://doi. org/10.1093/aje/kwp425 PMID: 20106935

18. Wu Y, Jiang X, Wang S, Jiang W, Li P, Ohno-Machado L. Grid multi-category response logistic models. BMC Med Inform Decis Mak. 2015;15(1):10. https://doi.org/10.1186/s12911-0150133-y PMID: 25886151

19. Carayol M, Bucourt M, Cuesta J, Blondel B, Zeitlin J. Les femmes de Seine-Saint-Denis ont-elles un suivi prénatal différent de celui des autres femmes d'île-de-France? [Do women from Seine-Saint-Denis have different prenatal care compared to other women in the region?]. J Gynecol Obstet Biol Reprod (Paris). 2015;44(3):258-68. https://doi.org/10.1016/j. jgyn.2014.02.006 PMID: 24702967

20. Feijen-de Jong El, Jansen DE, Baarveld F, van der Schans CP, Schellevis FG, Reijneveld SA. Determinants of late and/or inadequate use of prenatal healthcare in highincome countries: a systematic review. Eur J Public Health. 2012;22(6):904-13. https://doi.org/10.1093/eurpub/ckr164 PMID: 22109988

21. Frew PM, Parker K, Vo L, Haley D, O'Leary A, Diallo DD, et al. HIV Prevention Trials Network 064 (HTPN) Study Team. Socioecological factors influencing women's HIV risk in the United States: qualitative findings from the women's HIV Serolncidence study (HPTN 064). BMC Public Health. 2016;16(1):803. https://doi.org/10.1186/s12889-016-3364-7 PMID: 27530401

22. Conseil économique, social et environnemental. Le travail à temps partiel. [Economic, Social and Environmental Council. Part-time work]. Paris: Les éditions des journaux officiels. [Accessed 12 Oct 2018]. Available from: https://www.lecese.fr/ travaux-publies/le-travail-temps-partiel-o
23. Conseil national du sida et des hépatites virales (CNS). Costagliola D. Epidémiologie de l'infection à VIH en France. Prise en charge médicale des personnes vivant avec le VIH - Recommandations du groupe d'experts sous la direction du Pr Philippe Morlat. [Epidemiology of HIV in France. Medical management of people living with HIV directed by Philippe Morlat]. Paris: CNS; [Accessed 22 Jan 2019]. French. Available from: https://cns.sante.fr/actualites/ prise-en-charge-du-vih-recommandations-du-groupe-dexperts/

\section{License, supplementary material and copyright}

This is an open-access article distributed under the terms of the Creative Commons Attribution (CC BY 4.0) Licence. You may share and adapt the material, but must give appropriate credit to the source, provide a link to the licence and indicate if changes were made.

Any supplementary material referenced in the article can be found in the online version.

This article is copyright of the authors or their affiliated institutions, 2019. 